\title{
Near tip strain evolution under cyclic loading
}

\author{
J. Tong, Y.-W. Lu, B. Lin \\ University of Portsmouth, UK
}

Y. H. Tai

Rolls-Royce plc, UK

J.R. Yates

University of Manchester, UK

\begin{abstract}
The concept of ratchetting strain as a crack driving force in controlling crack growth has previously been explored at Portsmouth using numerical approaches for nickel-based superalloys. In this paper, we report the first experimental observations of the near-tip strain evolution as captured by the Digital Image Correlation (DIC) technique on a compact tension specimen of stainless steel 316L. The evolution of the near-tip strains with loading cycles was studied whilst the crack tip was maintained stationary. The strains were monitored over the selected distances from the crack tip for a given number of cycles under an incremental loading regime. The results show that strain ratchetting does occur with load cycling, and is particularly evident close to the crack tip and under higher loads. A finite element model has been developed to simulate the experiments and the simulation results are compared with the DIC measurements.
\end{abstract}

KEYwORDS. DIC; FE; Ratchetting; Crack tip mechanics; Fatigue crack growth.

\section{INTRODUCTION}

$\checkmark$ he concept of ratchetting strain as a crack driving force in controlling crack growth has been investigated utilising a variety of constitutive models, including elastic-plastic, visco-plastic and crystal-plastic formulations, for nickelbased superalloys [1-3]. Crack tip deformation fields were examined for both stationary and growing cracks at room and $650^{\circ} \mathrm{C}$ using the finite element method. Distinctive strain ratchetting behaviour near the crack tip was identified in all cases, leading to progressive accumulation of tensile strains normal to the crack growth plane. It was hypothesised that this tensile strain may be responsible for material separation leading to crack growth. Most recently the concept has been applied successfully [4] to fatigue crack growth of a nickel alloy in vacuum at a range of temperatures, where the influence of oxidation is removed. Although this latest work appears to be very encouraging, no direct experimental evidence is yet available to support this line of reasoning.

In this paper, we present the first series of experimental results on the measurement of the near-tip strains as a function of the number of loading cycles in a compact tension specimen of stainless steel 316L using the DIC method. Finite element analysis has also been carried out on the specimen and the near-tip strain results from the simulation are compared with those obtained experimentally. 


\section{EXPERIMENTAL METHODS}

$\mathrm{T}$

he material used for the investigation was stainless steel 316L. A compact tension (CT) specimen was employed with a width of $56 \mathrm{~mm}$, a thickness of $7 \mathrm{~mm}$ and a machined notch size of $24 \mathrm{~mm}$. An average grain size of the material along the rolling direction was found to be approximately $28.5 \mu \mathrm{m}$. The specimen was pre-cracked first in a servo-hydraulic test machine under cyclic tension, allowing a crack growth of $\sim 2.05 \mathrm{~mm}$ to obtain a final crack length of $\sim 26.05 \mathrm{~mm}$. The cyclic testing was then conducted at constant load amplitude with the range of load increased after a given number (20) of cycles, as shown in Fig. 1. The evolution of the strain fields near the crack tip was monitored during the cyclic loading using the digital image correlation (DIC) technique. The DIC system employed is a stereomicroscope system, Vic-3D Micro ${ }^{\mathrm{TM}}$ by Correlated Solutions [5]. Speckle patterns were painted on the specimen surface to facilitate the image analysis, and a resolution of 1224 x 1024 pixels was achieved through the use of the cameras coupled with the microscope. Four series of tests were conducted where the near-tip strains were monitored and recorded using the DIC method. A loading frequency of $0.1 \mathrm{~Hz}$ was used for the testing to allow sufficient time to collect the data. The images were captured at a framing rate of 5 per second for each cycle and about 50 images were recorded for each cycle. The field of view of the images was approximately $2.15 \times 1.80 \mathrm{~mm}$, giving a pixel size of $1.76 \mu \mathrm{m}$.

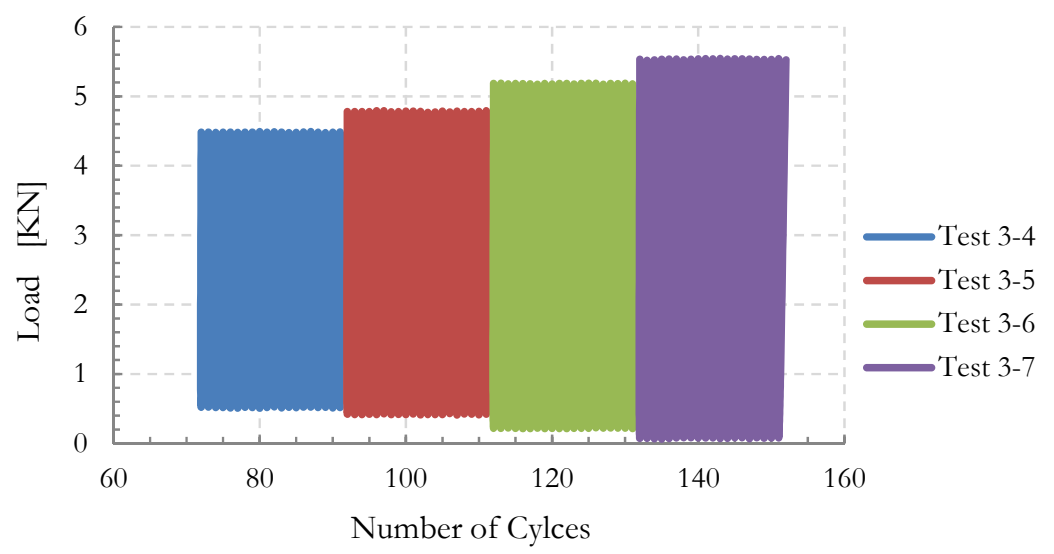

Figure 1: The cyclic loading scheme used for the experiment.

Digital image correlation has been used extensively to determine fracture parameters using the displacement data extracted from digital images $[6,7]$. The basic principles of DIC are to take a set of sequential images for a deformed object, with the first image taken before deformation serves as a reference and the subsequent images acquired at different deformation stages from the same region correlated with the reference image. The algorithm is based on the mathematical correlation of the intensity changes of the sequentially recorded digital images, and implemented through a procedure of finding the best correlation between the two images. Digital images are usually divided into smaller interrogation windows, or sub-sets, a matching process is performed on each of these sub-sets. A full field map of displacements/strains of each subset may be obtained when the correlation process is completed successfully. In the current work, LaVision $\mathrm{DaVis}$ 8.1.1 was employed to carry out the image correlation [8]. The size of the subsets was chosen as $28 \times 28$ pixels with a step size of 3 pixels, sufficient to provide a high spatial resolution and good image correlation quality as well as acceptable computational cost.

To study the near-tip strain evolution with load cycles, regions of interest near the crack tip were selected and strain distributions studied. Specifically, two points ahead of the crack and on the crack plane, $\mathrm{R}_{2}$ and $\mathrm{R}_{4}$, were monitored, where the distance to the crack tip, $\mathrm{R}_{2}=28.5 \mu \mathrm{m}$ and $\mathrm{R}_{4}=57 \mu \mathrm{m}$, as illustrated in Fig. 2. These values were selected to be either the same as the average grain size of the material $\left(\mathrm{R}_{2}\right)$ or about double the average grain size $\left(\mathrm{R}_{4}\right)$. The strain data at each location were obtained from an average value of multiple points within a $25 \mu \mathrm{m}$ x $25 \mu \mathrm{m}$ square. During the loading cycles, the crack length was also monitored and corrected post testing when micro crack growth was detected, such that the values of $R_{2}$ and $R_{4}$ stay the same throughout the tests. Micro-crack growth was indeed detected during some of the loading sequences (Test series 3-1 to 3-3, omitted in Fig. 1). These were excluded in the subsequent ratchetting analyses. 


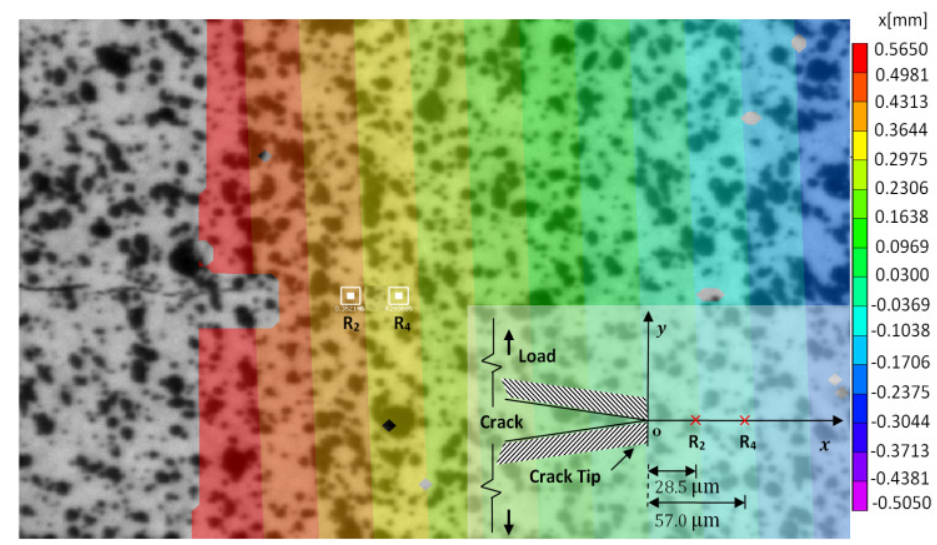

Figure 2: The random speckle pattern on the specimen and a typical displacement map extracted from the DIC measurement. The locations of $R_{2}$ and $R_{4}$ are illustrated with respect to the crack tip.

\section{FINITE ELEMENT ANALYSES}

$\mathrm{F}$ inite element analyses were carried out on the CT specimen using ABAQUS [9] under plane stress loading conditions to obtain the near-tip strain distribution on the specimen surface, and the results were compared with those measured by the DIC.

\section{Material model}

The material model by Lemaitre and Chaboche [10] was adopted where both isotropic and nonlinear kinematic hardening rules were used to describe the monotonic and the cyclic behaviour of SS316L [11, 12]. The equivalent von Mises stress is defined as:

$$
f(\sigma-\alpha)=\sqrt{\frac{3}{2}\left(s-\alpha^{d e v}\right):\left(s-\alpha^{d e v}\right)}
$$

where $\alpha^{\text {dev }}$ is the deviatoric part of the back stress and $S$ is the deviatoric stress tensor. The size of the yield surface is defined using a simple exponential law:

$$
\sigma^{0}=\sigma_{0}+Q_{\infty}\left(1-e^{-b \bar{\varepsilon}^{p l}}\right)
$$

where $\sigma_{0}$ is the size of the yield surface at zero plastic strain, $Q_{\infty}$ and $b$ are isotropic hardening material parameters. The equivalent plastic strain is given by:

$$
\bar{\varepsilon}^{p l}=\frac{1}{1-\nu} \sqrt{\frac{1}{2}\left[\left(\varepsilon_{1}-\varepsilon_{2}\right)^{2}+\left(\varepsilon_{2}-\varepsilon_{3}\right)^{2}+\left(\varepsilon_{3}-\varepsilon_{1}\right)^{2}\right]}
$$

The evolution of the kinematic hardening component is defined as:

$$
\dot{\alpha}=C \dot{\bar{\varepsilon}}^{p l} \frac{1}{\sigma^{0}}(\sigma-\alpha)-\gamma \alpha \dot{\bar{\varepsilon}}^{p l}+\frac{1}{C} \alpha \dot{C}
$$

where $\alpha$ is the back stress, and are material parameters, and is the rate of change of $C$ with respect to temperature and field variables.

A total of five materials parameters are required to run the $\mathrm{FE}$ analyses: Initial yield stress $\sigma_{0}$; kinematic hardening parameters $C$ and $\gamma$ and isotropic hardening parameters $Q_{\infty}$ and $b$. The values of these parameters for SS316L were obtained using the experimental data for a strain range $\Delta \varepsilon=4.0 \%$ [13], and are summarised in Tab. 1 . 


\begin{tabular}{cccccc}
\hline$E$ & \multicolumn{2}{c}{ Kinematic hardening } & \multicolumn{2}{c}{ Isotropic hardening } \\
{$[\mathrm{GPa}]$} & $\begin{array}{c}\sigma_{0} \\
{[\mathrm{MPa}]}\end{array}$ & $\begin{array}{c}C \\
{[\mathrm{MPa}]}\end{array}$ & $\gamma$ & $\begin{array}{c}Q_{\infty} \\
{[\mathrm{MPa}]}\end{array}$ & $b$ \\
193 & 100 & 60000 & 280 & 200 & 6 \\
\hline
\end{tabular}

Table 1: The material parameters for SS316L [13].

\section{The finite element model}

The compact tension specimen as used in the experiment was modelled using the finite element method (ABAQUS). Due to symmetry of the geometry and the loading, only half of the specimen was meshed with 4-noded quadrilateral plane stress elements, as shown in Fig. 3. Finer elements were generated around the crack-tip area $(\Delta \approx 1.8 \mu \mathrm{m})$ and a rigid line was attached along the symmetry line to prevent the potential penetration of the crack flanks due to crack closure under cyclic loading. A mesh convergence study was carried out, and a mesh size of $3.6 \mu \mathrm{m}$ was found to be adequate such that the effect of mesh size on the stress-strain responses became negligible. The loading pin (marked in red in Fig. 3) was modelled as elastic and no slip was allowed between the loading pin and the specimen [14]. Cyclic tensile loading was applied at the centre of the pin according to the loading scheme (Fig. 1). A sequential crack tip node-release technique was applied to model the micro-crack growth, where nodes were released incrementally and set to the micro-crack growth length detected, otherwise the crack was assumed stationery. The strain values were calculated at the integration points and the average strain values were obtained for $R_{2}$ and $R_{4}$ over a square of $25 \mu \mathrm{m} \times 25 \mu \mathrm{m}$, similar to those obtained by the DIC method.

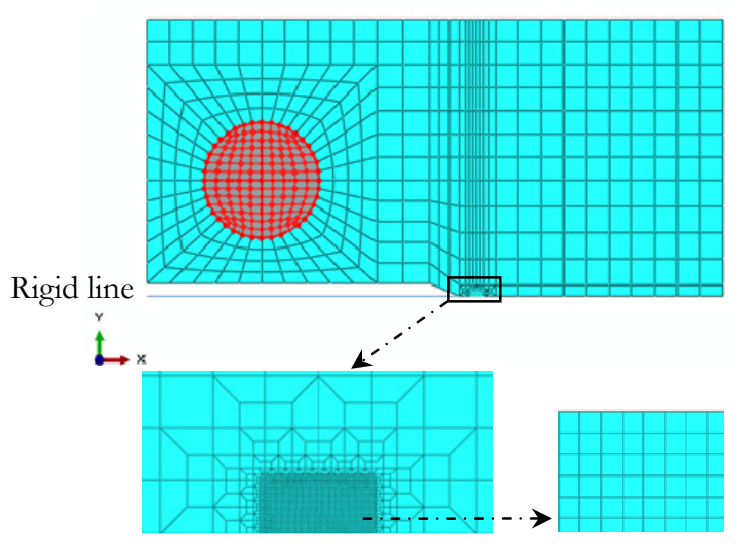

Figure 3: The FE mesh for the half-model of a CT-specimen, where a finer mesh $(\Delta \approx 1.8 \mu \mathrm{m})$ was used in the crack tip region.

\section{RESULTS AND DISCUSSION}

7 he strain evolutions with cycles are shown in Fig. 4 at $R_{2}$ and $R_{4}$ for the four test series (as shown in Fig. 1) from both the DIC and the FE analyses. It is evident from both analyses that tensile strains increase with the number of cycles in all load cases, although the FE analyses appear to predict higher responses than those from the DIC. A closer agreement between the two is achieved at $\mathrm{R}_{2}$, as opposed to $\mathrm{R}_{4}$, indicating that grain size might serve as a suitable candidate as a "critical distance".

Micro-crack growths were detected at some of the early test series, such that ratchetting behaviour could not be monitored on these occasions. These may be due to the pre-cracking load history or the notch effect. Further work is being carried out on controlled crack growths so that the relation between the ratchetting strain and the micro-crack growth may be explored. 


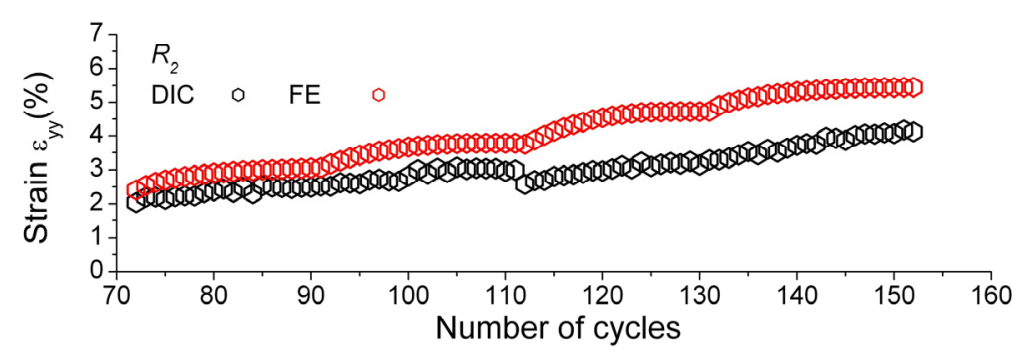

(a)

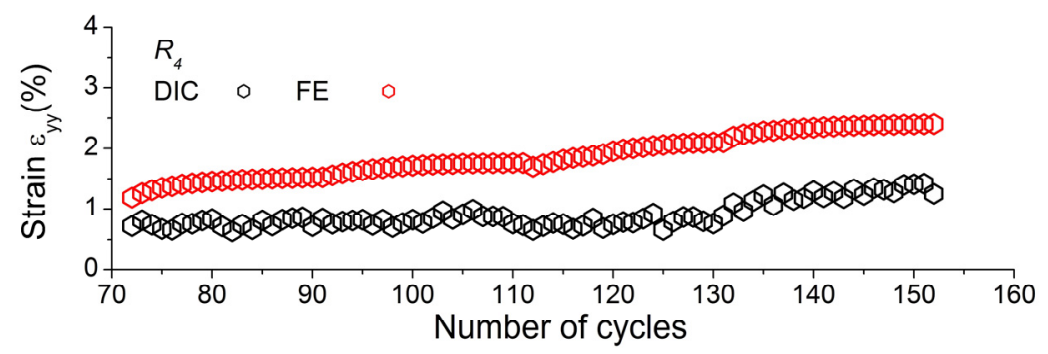

(b)

Figure 4: Strain responses at (a) $R_{2}$ and (b) $R_{4}$ with the number of cycles for the four test series (Fig. 1), comparison of the results from the DIC and the FE analysis.

\section{CONCLUSIONS}

$\mathrm{W}$

e report the first experimental evidence of the near-tip strain evolution as captured by the Digital Image Correlation on a compact tension specimen of stainless steel 316L. The evolution of the near-tip strains with loading cycles was monitored at selected load levels whilst the crack tip remains stationery. The results clearly show that strain ratchetting occurs with cycle, and is particularly evident close to the crack tip and under higher loads. Finite element analyses have also been carried out, and the results compare favourably with those measured at a distance about the grain size.

\section{REFERENCES}

[1] Tong, J., Zhao, L.G., Lin, B., Ratchetting strain as a driving force for fatigue crack growth, Int. J. Fatigue, 46 (2013) 49-57.

[2] Zhao, L.G., Tong, J., A viscoplastic study of crack-tip deformation and crack growth in a nickel-based superalloy at elevated temperature, J. Mech. Physics Solids, 56 (2008) 3363-3378.

[3] Zhao, L.G., Tong, J., Byrne, J., The evolution of the crack tip stress-strain fields and plasticity induced crack closure revisited, Fatigue Fracture Engng. Mater. Struc., 27 (2003) 19-29.

[4] Tong, J., Cornet, C., Lin, B., Zhao, L.G., Unpublished results, (2012).

[5] http://www.correlatedsolutions.com/index.php/products/vic-3d-2012/microscopy, (2012)

[6] McNeill, S.R., Peter, W.H., Sutton, M.A., Estimation of stress intensity factor by digital image correlation, Engineering Fracture Mechanics, 28(1) (1987) 101-112.

[7] Durig, B., Zhang, F., McNeill, S.R., Chao, Y.J., Peters III, W.H., A study of mixed mode fracture by photoelasticity and digital image analysis, Optics and Lasers in Engineering, 14(3) (1991) 203-215.

[8] LaVision GmbH, StrainMaster Mannual DaVis 8.1, Gottingen, Germany, (2012).

[9] ABAQUS 6.8, Hibbitt Karlsson and Sorensen Inc, Providence, RI, (2009).

[10] Lemaitre, J., Chaboche, J.L., Mechanics of Solid Materials, Cambridge University Press, (1990). 
[11] Chaboche, J.L., Rousselier, G., On the plastic and viscoplastic constitutive equations-Part II: Application of internal variable concepts to the 316 stainless steel, Transactions of the ASME, Journal of Pressure Vessel Technology, 105 (1983) 159-64.

[12] Chaboche, J.L., Constitutive equations for cyclic plasticity and cyclic viscoplasticity, International Journal of plasticity, 5 (1989) 247-302.

[13] Van Eeten, P., Nilsson, F., Constant and variable amplitude cyclic plasticity in 316L stainless steel, Journal of Testing and Evaluation, 34 (2006) 298-311.

[14] Kuntiyawichai, K., Burdekin, F.M., Engineering assessment of cracked structures subjected to dynamic loads using fracture mechanics assessment, Engineering Fracture Mechanics, 70 (2003) 1991-2014. 